\title{
A study to assess and compare the level of adherence of IMNCI guidelines among ANMs and ASHA-Sahyoginis in the IMNCI programme implemented in rural areas of Rajasthan
}

\author{
Yadav $\mathbf{A}^{1}$, Batra $\mathrm{K}^{2}$ \\ ${ }^{1}$ Ashok Yadav, Nursing Tutor, Government College of Nursing, Jaipur, Rajasthan, India, ${ }^{2}$ Kiran Batra, Principal and \\ Professor, Silver Oaks College of Nursing, Abhipur, Punjab, India
}

Address for Correspondence: Mr. Ashok Yadav, Email: yadav_ashok2006@yahoo.com

\begin{abstract}
Introduction: The study was undertaken to assess and compare the adherence to IMNCI guidelines among ANMs and ASHA-Sahyoginis in terms of the following five elements of case management process of IMNCI-assessment, classification, treatment, counselling and referrals of sick young infants and children. Methods: Data obtained from 520 IMNCI workers (including 390 ASHA-Sahyoginis and 130 ANMs) working at subcenter / village / anganwadi kendras of the initially and fully IMNCI implemented nine districts of Rajasthan. Multistage (cluster) with stratified proportionate sampling technique was adapted. Direct overt non-participatory observation technique with validated and reliable observation checklists were used to collect data. Results: Findings of the study reveals that $43 \%$ and $32 \%$ of ANMs showed overall adherence to IMNCI guidelines of young infants and children respectively - whereas only 19\% and 3\% of ASHA-Sahyoginis showed overall adherence to IMNCI guidelines of young infants and children respectively. Comparative analysis of ANM's and ASHA-Sahyogini's adherence clearly indicated that $43.08 \%$ and $31.54 \%$ of ANMs showed overall adherence in comparison to $18.72 \%$ and $2.56 \%$ of ASHA-Sahyogini's overall adherence to IMNCI guidelines for young infants and children respectively. Conclusion: Findings of some previous studies and reports of UNICEF, WHO and Ministry of Health \& Family Welfare (MOHFW) Government of India are found to be in line with the current study. The low level of adherence particularly among ASHA-Sahyoginis is because of lack of motivation, monitoring and supervision. Apart from the weak monitoring and supervision, overburden of ANMs with various programmes, maintenance of several types of records and reports serves as a major hindrance in the adherence of ANMs to IMNCI guidelines.
\end{abstract}

Key words: IMNCI Guidelines, Adherence, IMNCI Workers, Young Infants, Children

\section{Introduction}

Although the individualized interventions like childhood vaccinations, oral rehydration therapy, effective use of antibiotics have been able to reduce childhood deaths but the accumulated evidences suggest that an integrated approach is needed to manage sick children to achieve better outcomes. Child health programmes need to move beyond single disease to address the overall health and well-being of the child. Because many children present with overlapping signs and symptoms of diseases, a single diagnosis can be difficult, and may not be feasible or appropriate. This is

Manuscript received $10^{\text {th }}$ May 2016

Reviewed: $24^{\text {th }}$ May 2016

Author Corrected: $8^{\text {th }}$ June 2016

Accepted for Publication $20^{\text {th }}$ June 2016 especially true for first level health facilities where examinations involve few instruments, negligible laboratory tests and no x-ray. [1] During the mid 1990s, the World Health Organization (WHO) in collaboration with UNICEF and many other agencies, institutions and individuals, responded to this challenge by developing a strategy known as the Integrated Management of Childhood Illness (IMCI). Although the major reason for developing the IMCI strategy stemmed from the needs of curative care, the strategy also addresses aspects of nutrition, immunization and other important elements of disease prevention and health promotion. The Government of India recognized the need to strengthen child-health activities in the country and 
decided to launch IMCI. A core group was constituted comprising representatives from Indian Academy of Paediatrics (IAP), National Neonatology Forum of India (NNF), National Anti-Malaria Program (NAMP). Department of Women and Child Development (DWCD), Child in Need Institute (CINI), WHO, UNICEF, eminent paediatricians and Neonatologists and representatives from the Ministry of Health and Family Welfare (MOHFW) Government of India [2]. The generic IMCI guidelines were adapted and the Indian version was named Integrated Management of Neonatal and Childhood illness (IMNCI). The major adaptations were as follows $[1,2]$ :

The entire age group of 0 to 59 months (as against 2 months to 59 months in IMCI) was included to address the neonatal mortality challenge. The order of training was reversed, starting from young infants (0-2 months) to the older child ( 2 months-5 years). The total duration of training was reduced from 11 days to 8 days out of which, half of the training time was earmarked for the management of the young infants up to 2 months, which contributes to a lot to the mortality rate. Home-based care of newborns and young infants was included. The management guidelines were made consistent with the current policies of Ministry of Health and Family Welfare (MOHFW), Department of Women and Child Development (DWCD) and National Anti-malaria Programme (NAMP). Separate training material, eg : training module, chart booklet, photo booklet and video was developed for the health and nutrition workers and for the physicians. The training material for the health workers was also translated in Hindi, Marathi, Gujarati and Tamil [2]. IMNCI implies the case management process approach which includes the five elements i.e. assessment, classification, treatment, counseling and referral of both the age groups named young infants (upto 2 months) and children (2 months to five years) $[1,2]$.

The IMNCI strategy provides home-based care for the newborns and the young infants. The home care component for newborns aims to promote exclusive breast feeding, preventing hypothermia, improvement in the recognition of illnesses by parents, and reducing delays in seeking care. As per the IMNCI protocol, a health worker has to make at least three home visits for all the newborns, the first visit should be within 24 hours of the birth, second on day 3-4 and third at day 7-10. Three additional visits are scheduled for the newborns with low birth weight at day 14, 21 and 28 $[1,2]$. In Rajasthan IMNCI Program was initiated from district Jhalawar in December 2003 which was extended to Tonk in August, 2005. Between May 06 to Feb. 07 it was extended across seven new districts namely Baran, Bundi, Sawaimadhopur, Kota, Karauli, Bharatpur and Dholpur. In 2007-08, the program was initiated in another nine districts - Ajmer, Bhilwara, Udaipur, Dungarpur, Banswara, Rajsamand, Pali, Jalore and Sirohi. Till the date of data collection Programme was implemented fully in the first implemented nine districts of Rajasthan. At the grass root level or first point of contact the IMNCI is implemented through IMNCI workers - ANMs and ASHA-Sahyoginis. [3] Though both of these are given a training of 8 days but they differ in their education, social status and other background factors. So, it would be important to identify which of these two groups of grass root IMNCI workers, adhere more to IMNCI guidelines? and whether the background factors like age, education, marital status, and work experience have any effect on the adherence to IMNCI guidelines.

National Family Health Surveys (NFHS) showed a decreasing trend in IMR, declining from 80 (infants deaths per thousand live births) in 1998-99 [4,5] to 65 in 2005-06. [4,5] Registrar general of India has released the latest estimates of Infant Mortality Rate (IMR), Crude Birth Rate (CBR), Crude Death Rate (CDR) for India and all states / Union territories, according to which IMR of Rajasthan has declined from 65 to 63/1000 live births in 2008 [6]. IMR in rural areas has declined from $72 / 1000$ in 2007 to $69 / 1000$ in 2008 and in urban areas it has declined from 40/1000 in 2007 to $38 / 1000$ in 2008. [6] Neonatal mortality rate in Rajasthan is 44/1000 live births (India-36/1000 live births), contributing to about $50 \%$ of all deaths in childhood. Despite massive investments under RCH-II Programme and NRHM and visible improvements in health system, the decline in IMR has been inadequate : much less than that would be required to reach the XI plan goals of reducing IMR to 32/1000 live births by the year 2012. While there has been some decline in the infant mortality from one month to one year of life, the Newborn mortality has remained almost static for the past seven years. The nutritional status of children in Rajasthan has improved substantially since NFHS-2 [7], but $44 \%$ of its children below five years of age are still underweight (NFHS-3) [5]. The problem of anemia among children requires radical changes in prophylactic measures as $79.6 \%$ of the children under-3 years in rural Rajasthan are still anaemic (NFHS-3). [5] According to District Level Household Survey (DLHS3) [7]. (2007-08) $75.6 \%$ of children of ARI / fever and 
$59.7 \%$ of children with diarrhoea had access to treatment. The usage of ORS among children suffering from Diarrhoea was $30.6 \%$ in 2007-08 (DLHS-3) [7].

Keeping in view the child health scenario in Rajasthan, variety of child health programmes running in the state, much of attention paid and monitory expenditure done on IMNCI in Rajasthan, some of the previous research studies, WHO suggestions and better implementation of IMNCI in Rajasthan, the Researcher felt a strong need to conduct a research on assessing the adherence to the intelligently prepared IMNCI guidelines among the grass root IMNCI workers, who shoulders the responsibility of bringing down the Neonatal, Infant and Child Mortality Rates in Rural Rajasthan. Success of IMNCI Programme lies in various factors like the cost effectiveness of the programme, adequate supervision of the health workers, acceptability of the guidelines by the health workers, knowledge, skills and motivation to the health workers, adherence of the health workers to the intelligently prepared guidelines, socio-cultural barriers encountered by the health workers and beneficiaries and so on [8].

\section{Method}

The research approach selected for this study was a Quantitative Research approach. Descriptive research design comparative and evaluative in nature was considered for the study. The study was carried out in the rural areas of the nine districts of Rajasthan where the IMNCI was initially implemented and implemented almost fully. They are namely - Tonk, Sawaimadhopur, Baran, Bundi, Kota, Karauli, Jhalawar, Dholpur and Bharatpur. The Data Collection was done at the subcenters and Anganwadi Kendras and in case young infants and children were not available at subcentres and Anganwadi Kendras, home visits were made along with the selected ANMs and ASHA-Sahyoginis. In this study the population comprised of all the ANMs and ASHA-Sahyoginis who were trained in IMNCI and working in rural areas (i.e. sub-centers and Anganwadi Kendras) of all the blocks of nine districts of Rajasthan. There were 51 blocks in the selected nine districts of Rajasthan and an estimated total of 5924 grass root workers trained in IMNCI including 1713 ANMs and 4211 ASHA-Sahyoginis working in all these blocks. Sampling was done based on the inclusion criteria. Multistage (cluster) with stratified proportionate sampling technique was adopted. In the first stage half of the (clusters) blocks (i.e. 26 blocks out of 51 blocks) were sampled randomly through lottery method. Within each selected (cluster) block stratified proportionate sampling technique was applied. 5 ANMs and 15 ASHA-Sahyoginis were selected within each block. All five ANMs in a block were randomly selected through lottery method and 3 ASHA-Sahyoginis working under the subcenter of the selected ANM were also selected randomly through lottery method. (A minimum ratio of 1:3 between ANMs and ASHA-Sahyoginis, as recommended by the government). In case any selected ANM or ASHA-Sahyogini was not traced out or not cooperative / not willing to participate in the study, the geographically nearest i.e. ANM or ASHA-Sahyogini of the nearby village or of the same village was selected. Number of such ANMs and ASHA-Sahyoginis were 9 and 30 respectively. All these reselected or replaced ANMs and ASHA-Sahyoginis were from the same block of the initially / randomly selected ANM/ASHA-Sahyogini. Study has been conducted on a large sample size i.e. 520 IMNCI workers (including 130 ANMs and 390 ASHA-Sahyoginis in the ratio of 1:3). All the IMNCI workers were observed on their adherence to the case management process of both the age groups of children i.e. young infants and children. An observation checklist was developed to assess IMNCI workers (i.e. ANMs and ASHA-Sahyoginis) adherence to IMNCI guidelines for young infants (upto 2 months of age). Another observation checklist was developed to assess ANMs and ASHA Sahyoginis adherence to IMNCI guidelines for children (2 months to 5 years of age) Direct overt non participatory observation technique was considered to be the most suitable and appropriate in order to assess both the groups of IMNCI workers i.e. ANM's and ASHASahyogini's adherence to the IMNCI guidelines for both the age groups of children i.e. upto 2 months (young infants) and 2 months to 5 years (children). Observation of adherence of IMNCI workers was done only once. To ensure the content validity of the tool, the observation checklists were reviewed by 21 experts from the field of public health, IMNCI experts, trainers, planners and implementers from nursing and medical profession.

Inter-observer method was considered to be the appropriate method to compute the reliability of the observation checklists. The scores obtained by both the observers were computed using Pearson's Product moment coefficient of correlation ' $r$ ' to check the agreement between the observers. The value of ' $r$ ' obtained was found to be 0.98 and 0.96 for the observation checklist for young infants and children respectively. Permission was obtained to conduct the 
study from Additional Director (Administration) Medical and Health Services, Rajasthan Jaipur. He is the appointing authority for all non-gazetted nurses including ANMs. Permission was also obtained to collect data from the Director, Reproductive and Child Health (RCH), Government of Rajasthan, Department of Family Welfare and National Rural Health Mission. $\mathrm{He}$ is the authority under whom the IMNCI Programme is running in Rajasthan. Final Data were collected from the sampled study subjects of the sub centers / villages from $1^{\text {st }}$ August, 2011 to $1^{\text {st }}$ January 2012. Direct overt participatory observation technique was used and recorded with the help of validated and reliable observation checklists.

\section{Results}

$37.69 \%$ and $33.08 \%$ of ANMs were of the age groups 35 to 44 years and 25 to 34 years respectively. $55.38 \%$ of ASHA-Sahyoginis were less than 25 years of age. $60 \%$ of ANMs had educational qualification of $10^{\text {th }} \mathrm{Std}$. and $73.33 \%$ of ASHA-Sahyoginis had $8^{\text {th }}$ Std. as their educational qualification. $74.62 \%$ of ANMs and $73.59 \%$ of ASHA-Sahyoginis found to have 3 to 4 years of experience after undergoing IMNCI training $97.69 \%$ of ANMs and $100 \%$ of ASHA-Sahyoginis were found to be married. $43 \%$ of ANMs adhered to IMNCI guidelines for young infants as against the test proportion of $50 \%$ which was found to be not statistically significant adherence. $32 \%$ of ANMs adhered to IMNCI guidelines for children, which was statistically significant adherence at 0.05 level of significance. $19 \%$ of ASHA-Sahyoginis significantly adhered to the IMNCI guidelines for young infants whereas only $3 \%$ of ASHA-Sahyoginis significantly adhered to the IMNCI guidelines for children at 0.05 level of significance. Two proportion $\mathrm{Z}$ test was applied and tested at 0.05 level of significance. It was found that greater number of ANMs (43.08\%) in comparison of ASHA-Sahyoginis (18.27\%) adhered (overall) to IMNCI guidelines for young infants, significantly at 0.05 level of significance. Greater number of ANMs $(31.54 \%)$ in comparison of ASHA-Sahyogini's (2.56\%) showed statistically significant. Rank-Biserial coefficient of correlation was computed and $\mathrm{P}$ value tested at 0.05 level of significance to identify the association of ANM's and ASHA-Sahyoginis adherence to IMNCI guidelines for young infants and children with the selected background factors i.e. age, educational qualification, duration of experience after undergoing IMNCI training and marital status. The association of ANMs adherence to IMNCI guidelines for young infants was found to be statistically significant negative association with educational qualification and statistically not significant with age, duration of experience after IMNCI training and marital status. The association of ANM's adherence to IMNCI guidelines for children and the selected background factors indicated that except the negative association of adherence with educational qualification, other background factors i.e. age, duration of experience after IMNCI training and marital status did not show statistically significant association. The association of ASHA-Sahyoginis adherence to IMNCI guidelines for young infants and selected background factors indicated that none of the background factors i.e. age, educational qualification, duration of experience after IMNCI training and marital status had statistically significant association with the adherence. The association of ASHA-Sahyogini's adherence to IMNCI guidelines for children and selected background factors indicated that the adherence with none of the selected background factors had statistically significant association.

\section{Discussion}

The Government of India implemented an adapted version of IMCI as IMNCI on pilot basis in six districts: Shivpuri (Madhya Pradesh), Osmanabad (Maharashtra); Vellore (Tamilnadu); Jhalawar (Rajasthan); Valsad (Gujarat) and Mayurbhanji (Orissa) (UNICEF/WHO 2003) [9]. The recent UN Millennium Project (UNMP) report recommended as a "Quick Win" a "massive training of Community based workers". Informal / community based health workers can play an important role in both preventive and curative interventions. Some experiences, e.g. from the Integrated Management of Childhood Illness programme suggests that community based workers need to be supervised and linked to formal health system to be most effective and to have impact on health outcomes. The literature also shows that merely training community health worker (CHWs) is not enough to ensure that they have an impact on health. Investment of time and expertise is required to analyse and define the work to be done by CHWs (Fred Abot, 2005) [10].

In the current study population, 38 percent of ANMs belong to the age group of 35 to 44 years and 33 percent belong to the age group of 25 to 34 years. Whereas 55 percent of ASHA - Sahyoginis belong to age group of less than 25 years. This well attributes the longer existence of ANMs in the health system as compared to the emergence of ASHA-Sahyoginis under National 
Rural Health Mission. ANMs possess minimum schooling of $10^{\text {th }}$ class backed up with formal education of auxiliary nurse midwives course whereas, ASHASahyoginis possess minimum schooling of $8^{\text {th }}$ class. In regard to the duration of experience after undergoing IMNCI training, it was found that 75 percent of ANMs and 74 percent of ASHA-Sahyoginis had 3 to 4 years of experience after undergoing IMNCI training. In the study area, the IMCNI trainings of the ASHASahyoginis and ANMs were conducted simultaneously. Bharani S, Parmar T et al (2012) indicated that $62 \%$ AWWs were $\leq 40$ years and $38 \%$ above 40 years, whereas $48 \%$ AWWs had 1 to 2 years of time duration before which IMNCI training was given in comparison to $52 \%$ having 2 to 5 years[11]. Baqui et al (2004) reported an evaluation of a five week training programme in Bangladesh for the assessment and management of sick new-borns using the IMCI algorithm and this study did not take up the background factors and consisted of evaluating only community health worker (CHW)[12]. From this, it is evident that background factors have been taken in consideration by earlier researcher but they have considered only community health workers namely anganwari worker, whereas in the current study, the researcher has included the background factors of ANMs and ASHASahyoginis. In the current study, the overall adherence to the IMNCI guidelines for young infants was $43 \%$ among ANMs and 19\% among ASHA-Sahyoginis. The overall adherence to the IMNCI guidelines for children was 32\% among ANMs and only 3\% among ASHASahyoginis. There are many papers that report adherence of ANMs and community health worker on specific disease conditions and one or two elements related to IMCI/IMNCI, but in the absence of any research study irrespective of disease condition and overall adherence (all the five elements of case management process of IMNCI), researcher could not establish any linkage with previous studies. However, Mohan P, Kishore B, Singh S et al (2011) studied that IMNCI home visit coverage reached only 64 percent of target population and those new-borns not reached were likely to be vulnerable [13]. This also reflects poor adherence to IMNCI. This is in line to the findings of the current study.

Pratinidhi et al (1986) studied that trained community Health Guides (CHGs) adhered to the training given to them on identifying risk factors and severity of illness and contributed towards reduction of neonatal mortality rate[14]. The study is in contrast to the findings of the current study. Chaudhary N, Mohanty P.N. and Sharma
M (2005) indicated that the improvement in assessment and classificationof young infants and children was not significant among AWWs after IMNCI training [15]. In context to the current study, in terms of assessment, classification, treatment, counselling and referral and overall adherence (young infants and children) ASHASahyogini's adherence was statistically significant low adherence. Herewith, the current study findings are supported by the earlier research. Also Manjula Datta (2001) [16] research study is in continuum to the current study findings.

In contrast to the present study, a community based meta-analysis by Sazawal A, Black R (2003) demonstrates the CHWs do have an impact on health outcomes[17]. Other studies have also reported that TBAs (trained birth attendants) and VHWs (village health workers) are most suitable community based health workers for ARI control programmes in developing countries [18].

Venkatachalam J, Aggarwal AK et al (2012) reproted the unsatisfactory adherence to IMNCI guidelines for management of children under five years of age [19]. Venkatachalam J, Kumar D et al (2011) revealed that the knowledge and skills of ANMs and AWWs significantly declined over a period of 3 years[20]. Similarly Jain S, Smriti (2009) in the performance analysis study in Madhya Pradesh identified numerous functional problems in effective implementation IMNCI [21]. Findings of all these studies evidently support the low level adherence of ANMs and ASHA-Sahyoginis to IMNCI guidelines. Gupta M, Venkatachalam J et al (2013) established that supportive supervision of health workers in Rajasthan, Bihar and Orissa increased their referral rates for young infants and sick children and also increased their post natal visits [22]. This justifies the one of the reasons of poor adherence in the current study.

However, the Ministry of Health \& Family Welfare MOHFW's (Government of India) evaluation of the progress of NRHM in Rajasthan, the $20082^{\text {nd }}$ "Common Review Mission", a lack of supervisory support and monitoring system for ASHA was identified as a major operational weakness of the programme[23]. The report supports the findings of the current study in terms of low level adherence of ASHASahyoginis to IMNCI guidelines. Another Report of Ministry of Health and Family Welfare (MOHFW) (2009) clearly suggests that the ASHAs require followup monitoring and on the job supervision and training to 
increase motivation and to improve performance [8]. Low level of adherence among ANMs and ASHA Sahyoginis and no significant association with the background factors are due to the weak supervision and monitoring. Under India Newborn Action Plan (INAP) by MOHFW, the Government of India has established a web based tracking system (Mother and Child Tracking System) to track every pregnant women and child till the age of 2 years. States have taken steps to improve quality of data for vital events including causes of death [24].

\section{Conclusion}

The study intended to assess and compare the adherence to IMNCI guidelines among the ANMs and ASHASahyoginis in the rural areas of Rajasthan. With the help of appropriate methodology and the appropriate statistics the findings of the study reveals the greater percentage of ANMs adhered in comparison to ASHASahyoginis to IMNCI guidelines for both the groups of children. In terms of the association of ANMs adherence with selected background factors, the adherence was found to be statistically significant negative association with educational qualification and no significant association with other background factors for both the age groups of children.

The association was found to be no significant in case of ASHA-Sahyoginis adherence to IMNCI guidelines of both age groups and the background factors. Although not much studies have been done on these areas but findings of some previous studies and reports of UNICEF, WHO and Ministry of Health \& Family Welfare (MOHFW), Government of India are found to be in line with the current study.

The low level of adherence particularly in case ASHASahyoginis is because of lack of motivation, monitoring and supervision. Apart from the weak monitoring and supervision, overburden of ANMs with various programmes, maintenance of several types of records and reports serves as a major hindrance in the adherence of ANMs to IMNCI guidelines.

Continuous training programmes at regular intervals and strengthening of supervision, monitoring and logistics supplies would serve as a boost in the adherence to IMNCI guidelines.

Funding: Nil, Conflict of interest: None initiated. Permission from IRB: Yes

\section{References}

1. WHO / MOHFW. Students handbook for IMNCI integrated management of neonatal and childhood illness. WHO and Ministry of health and family welfare Government of India, 2003; 1-7.

2. Ingle GK, Malhotra C. Integrated management of neonatal and childhood illness : An overview. Indian Journal of Community Medicine. 2007;32 (2):108-110.

3. Sanjana. IMNCI-Progress made in Rajasthan. Publication by Ministry of Health and Family Welfare. Government of Rajasthan. [cited on 2014 Oct. 21] Available from : http://www.rajswasthya.nic.in.

4. International Institute for Population Sciences IIPS and ORC Macro 2001. National family health survey NFHS-2, India; 1998-99: Rajasthan. Mumbai: IIPS 185187 [cited on 2009 Feb.17]Available from: http:///www. dhsprogram.com/pubs/pdf/FRIND2/FRIND2.pdf.

Website : http://www. nfhsindia.org.

5. International Institute for Population Sciences (IIPS) and ORC Macro International 2008. National Family Health Survey NFHS-3. India 2005-06; Rajasthan. Mumbai : IIPS : 56 [cited on 2009 Feb. 17] Available from:http://www.rchiips.org/nfhs / raj_state_report.pdf.

6. SRS Bulletin. Sample registration system. Registrar General of India, Vital Statistics Division, New Delhi. Monthly report October 2009; 44 (1) 1, 5. [cited on 2010 June 26] Available from: censusindia.gov.in/vital_ statistics/SRS_Bulletins/SRS-Bulletin-October-2009. pdf.

7. Ministry of Health and Family Welfare, Government of India. District level household and facility survey DLHS-3. International institute of population Sciences. Mumbai. India Rajasthan 2007-08; 5. [cited on 2009 Feb. 17] Available from: rchiips.org/pdf/rch3/ state/ Rajasthan.pdf.

8. Abel M, Almas S, Brown W. Sahni HV, Serotta R. Effect of Supportive Supervision on ASHA's performance under IMNCI in Rajasthan. UNICEF in colloboration with Indian Institute of Health Management Research (IIHMR) Jaipur. KCCI / 200908 ; 5-10, 17-20, 54.

9. UNICEF / WHO. Concept and Strategy Framework: Integrated Management of Neonatal and Childhood 
illness. Government of India, State Government, 2003; $1-16$.

10. Fred Abbatt. Scaling up health and education workers: Community health workers, literature review. DFID Health System Resource Centre, London. 2005: 18.

11. Bharani S, Parmar T, Kantharia N, Parmar R, Kharod N. A study to assess the implementation and effectiveness of IMNCI programme and evaluation of skills of rural anganwadi workers in Vadodara taluka. National Journal of Community Medicine. 2012; 3 (2): 207-212.

12. Baqui A, EI Arifeen $\mathrm{S}$ et al. Evaluation of Community Health Worker (CHW) skills to recognize and manage sick new borns in the community. APHA Conference, Washington DC. 2004; 24.

13. Mohan P, Kishore B, Singh S, Bahl R, Puri A, Kumar R. Assessment of implementation of integrated management of neonatal and childhood illness in India. J Health Popul Nutr. 2011 Dec;29(6):629-38.

14. Pratinidhi A, Shah U, Shrotri A, Bodhani N. Riskapproach strategy in neonatal care. Bull World Health Organ. 1986;64(2):291-7.

15. Chaudhary N, Mohanty PN, Sharma M. Integrated management of childhood illness (IMCI) follow-up of basic health workers. Indian J Pediatr. 2005 Sep; 72(9):735-9.

16. Datta M. Sensitivity and Specificity of Anganwadi workers diagnosis of danger signs as per IMNCI guidelines. J Health Popul Nutr. 2001; 19 (2):S111S154.

17. Sazawal S, Black RE; Pneumonia Case Management Trials Group. Effect of pneumonia case management on mortality in neonates, infants, and preschool children: a meta-analysis of communitybased trials. Lancet Infect Dis. 2003 Sep;3(9):547-56.

18. Bang AT, Bang RA, Baitule SB, Reddy $\mathrm{MH}$, Deshmukh MD. Effect of home-based neonatal care and management of sepsis on neonatal mortality: field trial in rural India. Lancet. 1999 Dec 4;354(9194):1955-61.

19. Venkatchalam J, Aggarwal AK, Gupta M, Sathya GR. Evaluation of IMNCI Practices among health care providers in a district of North India. IOSR Journal of Dental and Medical Sciences. 2012; 1 (6) : 46-50.

20. Venkatachalam J, Kumar D, Gupta M, Aggarwal AK. Knowledge and skills of primary health care workers trained on integrated management of neonatal and childhood illness: Follow-up assessment 3 years after the training. Indian Journal of Public Health. 2011; 55 (4) : 298-302.

21. Jain S, Samriti and Kumar R. Performance analysis of IMNCI in Madhya Pradesh. Vikas Samved Samiti Bhopal Madhya Pradesh 2009 : 1-4, 32, 41. [cited 2014, April 5] Available from http://www.mediaforrights.org.

22. Gupta M, Venkatachalam J, Goyal N, Kaur R, Goel $\mathrm{S}$, Kaur $\mathrm{M}$ et al. Models of supportive supervision for IMNCI Implementation in selected districts of Bihar, Orissa and Rajasthan in India. Indian Journal of Public Health Research and Development. 2013; 4 (1) : 224228.

23. DHMS Government of Rajasthan, Institute of Health Management Research Jaipur IIHMR, Norway India Partnership Initiative (NIPI), World Health Organization Country Office for India. Report on Short Programme review on child health in Rajasthan. GoR, IIHMR, NIPI, WHO 2010; 2-3.

24. MOHFW Government of India. Indian Newborn Action Plan (INAP). National Health Mission MOHFW GOI. September 2014; 18-77.

\section{How to cite this article?}

Yadav A, Batra K.A study to assess and compare the level of adherence of IMNCI guidelines among ANMs and ASHASahyoginis in the IMNCI programme implemented in rural areas of Rajasthan. Int J Med Res Rev 2016;4 (6):10101016.doi: 10.17511/ijmrr.2016.i06.25. 